\title{
Risk Factors of Spontaneous Pneumothorax in Kuwait
}

\author{
Adel K. Ayed $^{\mathrm{a}, \mathrm{b}} \quad$ Samer Bazerbashi $^{\mathrm{b}} \quad$ Muneera Ben-Nakhi ${ }^{\mathrm{b}}$ \\ Chezhian Chandrasekran $^{\mathrm{b}}$ Murgan Sukumar ${ }^{\mathrm{b}}$ Aiman Al-Rowayeh $^{\mathrm{b}}$ \\ Mohammed Al-Othman ${ }^{\text {b }}$ \\ ${ }^{a}$ Department of Surgery, Faculty of Medicine, Kuwait University, and ${ }^{b}$ Department of Thoracic Surgery, \\ Chest Diseases Hospital, Kuwait
}

\section{Key Words}

Body mass index $\cdot$ Smoking $\cdot$ Spontaneous pneumothorax $\cdot$ Weather

\begin{abstract}
Objectives: To determine the risk factors of spontaneous pneumothorax (SP) in Kuwait. Subjects and Methods: From January 2002 through December 2003, 254 consecutive cases with a diagnosis of SP were reviewed. Analyses of pneumothorax rates by age, sex, smoking, body mass index (BMI) and climatic conditions were evaluated. Results: Of the 254 patients, 242 (95\%) were male and 12 (5\%) were female; a larger proportion of 180 (88\%) were Kuwaitis and 74 (12\%) were expatriates. Two hundred and eight (82\%) episodes were regarded as primary SP and $46(18 \%)$ as secondary SP. The mean age was $24.5 \pm 5.8$ years for primary SP and 45.7 \pm 14.5 years for secondary SP. One hundred and ninety-six (77\%) individuals were current smokers. BMI in primary and secondary SP was 19.3 and 22.4, respectively ( $p<0.001$ ). There was no relationship between SP and climatic conditions (a rise or fall in temperature, humidity or atmospheric pressure). However, a slight increase in SP occurred in July, probably the hottest month in Kuwait. Conclusions: The data indicate that the most important risk factors of SP in Kuwait are smoking, low BMI and the male gender.
\end{abstract}

Copyright $\odot 2006$ S. Karger AG, Basel
(C) 2006 S. Karger AG, Basel

$1011-7571 / 06 / 0155-0338 \$ 23.50 / 0$

Fax +4161306 1234

E-Mail karger@karger.ch

www.karger.com
Accessible online at:

www.karger.com/mpp

\section{Introduction}

Spontaneous pneumothorax (SP) can be either primary SP due to the rupture of a subpleural bleb or secondary SP due to underlying lung disease, usually bullous emphysema. Primary SP has an estimated incidence of 7.418 cases, 1.2 and 6 cases per 100,000 population among men and women, respectively $[1,2]$. It typically occurs in tall, thin men between the ages of 10 and 30 years. The incidence of secondary SP is similar: approximately 6.3 and 2 cases per 100,000 population per year among men and women, respectively $[1,2]$. The peak incidence of secondary SP occurs later in life, between 60 and 64 years [2]. Much has been written about the classification, etiology, clinical features and management of SP but there is limited data about the epidemiology and quantitative information $[1,3]$. Constitutional factors such as gender and cigarette smoking could be responsible for the induction of SP. Previous studies have shown the possibility that climatic changes can be precipitating factors in the development of SP $[4,5]$. Although some information is available in the literature, little is known about the causative factors of SP in Arab countries, where smoking is common among males but rare in females. In 2003, using the International Classification of Diseases (ICD-10), it was estimated that SP occurred in 17.8 and 1.3 per 100,000 men and women in Kuwait, respectively [6]. As a step to- 
Table 1. Distribution of SP patients by age, sex, nationality and smoking

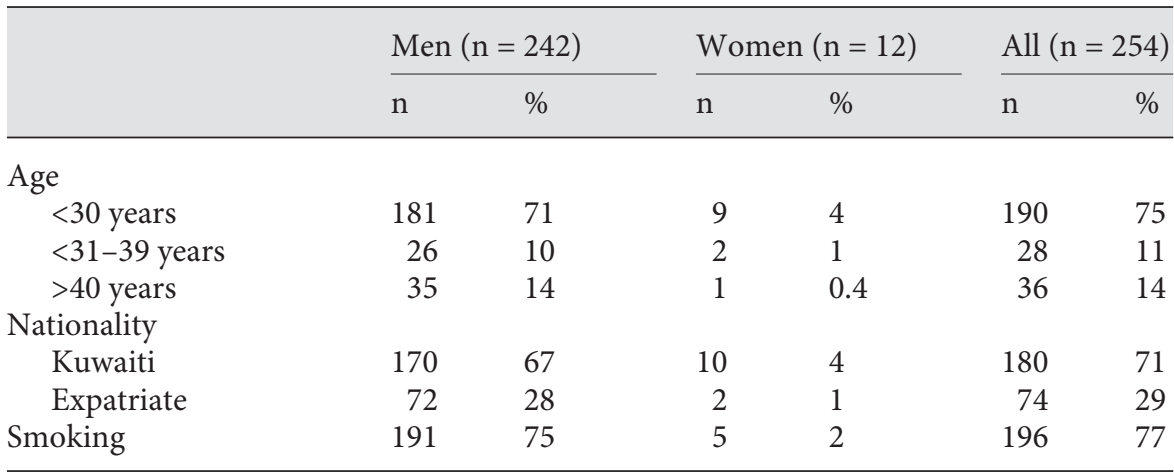

wards understanding the risk factors of SP in Kuwait, personal characteristics and climatic conditions associated with the occurrence of SP were analyzed.

\section{Subjects and Methods}

The State of Kuwait is situated in the northwestern corner of the Arabian Gulf. The total population in 2003 was about 2.2 million, of whom the Kuwaiti nationals constituted $37 \%$ and expatriates 63\% [7]. Expatriates from over 50 countries live in Kuwait. A majority of these are Arabs and Southeast Asians. Compared to the Western industrialized countries, Kuwait has a relatively young population structure: only about $9 \%$ of the Kuwaitis and $6 \%$ of the expatriates are aged $\geq 50$ years.

This study was conducted at the Chest Diseases Hospital, Kuwait, the center for the treatment of chest diseases in the country. All patients with a confirmed diagnosis of SP treated from January 1,2002 , to December 31,2003 , were included in the study. The diagnosis of SP was based on the presence of air in the pleural cavity on chest radiograph. All cases of iatrogenic or traumatic pneumothorax were excluded. Patients were identified from the hospital database, and the following information was extracted: age, sex, nationality, smoking status, body mass index (BMI), family history, classification of SP and month of attack.

\section{Climatic Data}

A computer record containing measurements of climatic variables (temperature in degrees Celsius, relative humidity as percent and atmospheric pressure as millibars) over the 2-year study period was obtained from the Kuwait Airport Authority.

\section{Statistical Analysis}

Data were expressed as number (and percentages) or mean \pm SD; data analyses were made using SPSS software for Windows version 11 packages (SPSS, Chicago, Ill., USA). The cut-off level for statistical significance was $\mathrm{p}<0.05$. The Student $\mathrm{t}$ test was used to assess the significance between the means of variables in two groups: primary and secondary SP. The Pearson $\chi^{2}$ test was used to ascertain the significance of association between two categorical variables. However, Fisher's exact test was used if any cell figure was less than 5 .

\section{Results}

A total of 270 patients with pneumothorax were admitted to the Chest Diseases Hospital; of these, 254 were considered eligible for inclusion in the study. The $16 \mathrm{ex}-$ cluded patients had iatrogenic pneumothorax. The distribution of patients by age, sex and nationality is given in table 1 . The mean age ( \pm SD) was $24.5 \pm 5.8$ and 45.7 \pm 14.5 years for primary and secondary SP, respectively. Of the 254 SP patients, 242 (95\%) were men and 12 (5\%) were women. The study population was $180(71 \%) \mathrm{Ku}-$ waitis and 74 (29\%) expatriates. The mean age for both types of SP for Kuwaiti and expatriates was $26.3 \pm 11.3$ and $33.1 \pm 10.5$ years, respectively, with an age range of $15-77$ years. But, overall, $74.8 \%$ of the patients were under the age of 30 years. The mean height and weight were $170.24 \mathrm{~cm}$ and $57.81 \mathrm{~kg}$, respectively. Of the 74 expatriates, almost half $(44 ; 59 \%)$ were of Arabian origin (Egypt, Syria, Jordan, Saudi Arabia, Lebanon and Oman) and 30 (41\%) from Southeast Asia (Pakistan, India, Iran, Bangladesh and the Philippines).

Two hundred and eight (82\%) episodes were regarded as primary SP, and $46(18 \%)$ as secondary SP (emphysema: 32; sarcoidosis: 5; tuberculosis: 5; histiocytosis X: 2 , and bronchial asthma: 2 ). There was a different frequency of occurrence between the right $(153 ; 60.2 \%)$ and left hemithorax $(101 ; 39.8 \%)$, with $\mathrm{p}=0.01$.

One hundred and ninety-six (77\%) were current smokers. Eight (3\%) patients had a family history of SP, 7 of which were primary episodes. SPs occurring in the same individual but at different times were considered as separate events; 84 (33\%) such episodes were recorded in this study.

The association of demographics and other factors with types of SP are shown in table 2. Primary SP was associated with a lower BMI than secondary SP: 19.3 versus 
Table 2. Primary association of demographics and other factors with type of SP

\begin{tabular}{|c|c|c|c|c|c|}
\hline & $\begin{array}{l}\text { Primary SP } \\
(\mathrm{n}=208)\end{array}$ & $\begin{array}{l}\text { Secondary SP } \\
(\mathrm{n}=46)\end{array}$ & OR & $95 \% \mathrm{CI}$ & $\mathrm{p}$ value \\
\hline \multicolumn{6}{|l|}{ Sex } \\
\hline Male & $198(95)$ & $44(96)$ & 0.9 & $0.1-4.2$ & 0.8 \\
\hline Female & $10(4)$ & $2(4)$ & & & \\
\hline \multicolumn{6}{|l|}{ Smoking status } \\
\hline Yes & $161(78)$ & $35(76)$ & 1.1 & $0.5-2.3$ & 0.8 \\
\hline No & $46(22)$ & $11(23)$ & & & \\
\hline BMI & $19.3 \pm 3.8$ & $22.4 \pm 5$ & 0.6 & -4.5 to 1.8 & $<0.001$ \\
\hline Height, cm & $170.78 \pm 9$ & $168.6 \pm 8.3$ & 1.5 & $0.7-5.1$ & 0.1 \\
\hline \multicolumn{6}{|l|}{ Nationality } \\
\hline Kuwaiti & $155(75)$ & $25(54)$ & 2.4 & $1.2-4.7$ & 0.006 \\
\hline Expatriates & $53(25)$ & $21(46)$ & & & \\
\hline \multicolumn{6}{|l|}{ Side } \\
\hline Left & $90(43)$ & $11(24)$ & 2.4 & $1.1-5$ & 0.01 \\
\hline Right & $118(57)$ & $35(76)$ & & & \\
\hline \multicolumn{6}{|l|}{ Age } \\
\hline$<30$ years & $182(87)$ & $8(17)$ & & & $<0.001$ \\
\hline $31-39$ years & $22(11)$ & $6(13)$ & & & (<30 vs. others) \\
\hline$>40$ years & $4(2)$ & $32(70)$ & & & \\
\hline \multicolumn{6}{|l|}{ Family history } \\
\hline Yes & $7(3)$ & $1(2)$ & 1.5 & $0.1-13$ & 0.5 \\
\hline No & $201(97)$ & $45(98)$ & & & \\
\hline \multicolumn{6}{|c|}{ Emergency admission } \\
\hline Yes & $161(77)$ & $27(59)$ & 2.4 & $1.4-2.7$ & 0.009 \\
\hline No & $47(23)$ & $19(41)$ & & & \\
\hline
\end{tabular}

22.4. The peak age for primary SP was below 30, while that for secondary SP was above 40 years. The time of year when SP occurred is given in figure 1, the value for July was significant for an increase in SP $(p=0.04)$. June was the month with the fewest cases, while May yielded the second most numerous cases. On grouping by quarters, similar rates were noted: January-March $(55 ; 22 \%)$, April-June (59; 23\%), July-September $(76 ; 30 \%)$ and October-December $(64 ; 25 \%)$. Overall, a slight increase in incidence of SP occurred in summer. No association was noted between fall in atmospheric pressure as well as changes in temperature and humidity and the occurrence of SP.

Fig. 1. Time of year of spontaneous pneumothorax (254 episodes) and frequency of cases.

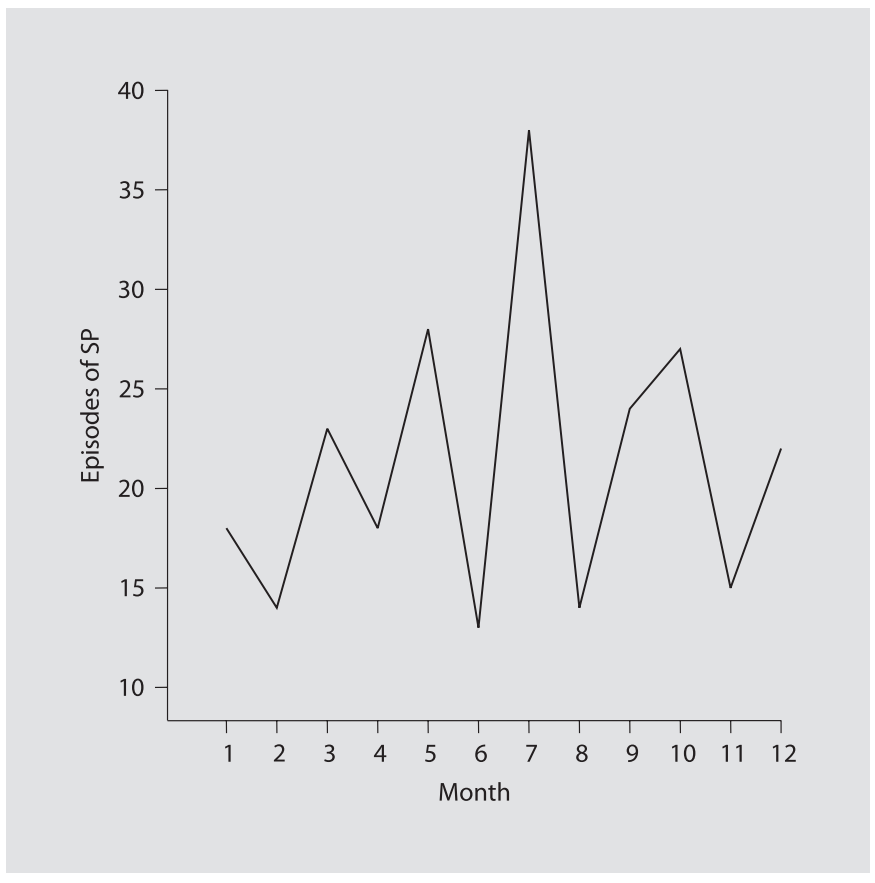




\section{Discussion}

SP occurs without any obvious preceding cause and remains a significant problem worldwide with its incidence increasing [2]. Few studies have been conducted in various countries in the past, and there is no consensus of opinion regarding causative factors of SP [2, 3]. Smoking is reported to be a significant risk factor for developing SP $[8,9]$. With smoking, the relative risk of developing pneumothorax is reported to increase 9- and 22-fold among men and women, respectively, and there is a dose-response relationship between the number of cigarettes smoked per day and the occurrence of pneumothorex [8]. The risk is higher among heavy smokers [9], similar to the findings in this study. Smoking cigarettes can increase the possibility of developing blebs and bullae, as well as causing bronchiolitis $[3,10]$. Whether or not cessation of cigarette smoking has an influence on reducing the likelihood of occurrence or recurrence of SP is not clear. Sadikot et al. [11] showed such an effect on cessation of smoking while Lippert et al. [12] did not show any decrease in the incidence of SP, except when patients stopped smoking for at least 1 year prior to developing the first SP.

Many underlying lung diseases can cause secondary SP. It is a potentially life-threatening condition, because most of these patients have an associated lung disease with limited cardiopulmonary reserve and poor lungcompliant resisting expansion [1]. The most common conditions associated with secondary SP described in the literature are chronic obstructive pulmonary disease and Pneumocystis carinii pneumonia related to infection with human immunodeficiency virus $[1,2]$. Other causes include: cystic fibrosis, sarcoidosis, tuberculosis, eosinophilic granulomatosis and idiopathic pulmonary fibrosis. In the present study, chronic obstructive pulmonary disease and bullous emphysema caused a majority of secondary SP. Other causes like P. carinii pneumonia or cystic fibrosis are rare in Kuwait.

In this study, patients with primary SP had a lower BMI (19.3) compared to the 37.0 reported by Sadikot et al. [11]. This difference in BMI could be explained by the physiological differences between the two population groups (Arabs vs. Europeans), confirming the importance of asthenic body build in the incidence of primary SP [13].

The occurrence of pneumothorax in the present study has a bimodal age distribution. The first peak was in the younger age group at $<30$ years, mainly with primary SP. The second peak was in the older age group ( $>40$ years), associated with secondary SP (table 2). This second peak is in parallel with the peak incidence of chronic obstructive pulmonary disease in the general population [1]. Findings in this study are similar to those reported in the literature with regard to primary SP $[2,12]$. Patients in the current study had a mean age of 24.5 and 45.7 years for primary and secondary SP, which is younger than that reported previously [2]. That a large majority (95\%) of our patients were men concurs well with what was documented in the previous studies $[2,13]$. Of all patients in the study, a large proportion (75\%) was young, $\leq 30$ years, partly reflecting the relatively young population structure of Kuwait.

It is a well-established fact that men are more prone to developing SP than women, with a male:female ratio of 6.2:1 and 3.2:1 for primary and secondary SP, respectively [2]. A partial explanation may be due to the fact that women in this study reported that they smoked less and started smoking at a later age than men [8]. Also, women have larger airways than men [14]. Therefore, airway obstruction that is characteristic of SP may manifest in the smaller airways of males at an early stage, accounting for the higher incidence of SP in men. Certain rare causes of SP are specific to women, such as catamenial pneumothorax and lymphangioleiomyomatosis, which occur characteristically between 24 and $72 \mathrm{~h}$ after the onset of menstruation. Our male:female ratio of 20.1:1 for SP events is by far higher than what is reported by others (from 2:1 to 7:1) [11,15]. The higher incidence of SP in men in the present study is supported by the association between primary SP, smoking and male predominance, because a large proportion of the men $(75 \%)$ were smokers compared to only $2 \%$ women in the total population analyzed.

There is a relatively high prevalence of smoking in the young Kuwaiti population, as evidenced by the overall prevalence of smoking reported in men: $34.4 \%$ as compared to $1.9 \%$ women [16].

This study did not show any association with the occurrence of SP and climatic conditions (weather, atmospheric pressure, temperature and/or humidity changes). However, a slight increase of SP in July, a very hot month in Kuwait, was noted (fig. 1). These findings are consistent with previous reports $[4,5]$ of no association between the development of SP and changes in atmospheric conditions. However, Scott et al. [17] observed a significant association between atmospheric pressure changes and the onset of SP. It is possible that changes in atmospheric pressure play an important role in the onset of SP, and those multiple factors might be responsible for the development of SP. 


\section{Conclusion}

The data indicate that, in Kuwait, the most important risk factors of SP are smoking, low BMI and the male gender.

\section{Acknowledgments}

We are grateful to Prof. M.A.A. Moussa from the Department of Community Medicine and Statistics for his help in the statistical analysis of these data.

The study was supported by an Environment Public Authority Research grant.

\section{References}

$>1$ Sahn SA, Heffner JE: Spontaneous pneumothorax. N Engl J Med 2000;342:868-874.

$\checkmark 2$ Gupta D, Hansell A, Nichols T, Duong T, Ayres JG, Strachan D: Epidemiology of pneumothorax in England. Thorax 2000;55:666671.

3 Scharmel FMNH, Postmus PE, Vanderschueren RGJRA: Current aspects of spontaneous pneumothorax. Eur Respir J 1997;10: 1372-1379.

4 Bulajich B, Subotich D, Mandarich D, Kljajich RV, Gajich M: Influence of atmospheric pressure, outdoor temperature, and weather phases on the onset of spontaneous pneumothorax. Ann Epidemiol 2005;15:185-190.

$>5$ Suarez-Varela MM, Martinez-Selva MI, Llopis-Gonzalez A, Martinez-Jimeno JL, PlazaValia P: Spontaneous pneumothorax related with climatic characteristics in the Valencia area (Spain). Eur J Epidemiol 2000;16:193198.

6 Health Kuwait, edition XL. Kuwait, Health and Vital Statistics Division, Ministry of Health, 2003
7 Annual Directory of Civil Information, Population, and Labour Force. Kuwait, Public Authority for Civil Information, 2003.

8 Bense L, Eklund G, Odont D, Wiman LG: Smoking and the increased risk of contracting spontaneous pneumothorax. Chest 1987; 92:1009-1012.

$\checkmark 9$ Nakamura H, Izuchi R, Hagiwara T, Izumi S, Konishiika J, Omura I, Sakai S, Shigematsu Y, Akutagawa M, Takeno Y: Physical constitution and smoking habits of patients with idiopathic spontaneous pneumothorax. Jpn J Med 1983;22:2-8.

10 Smit HJM, Deville WL, Schamel FMNH, Schreurs AJM, Sutedja TG, Postmus PE: Atmospheric pressure changes and outdoor temperature changes in relation to spontaneous pneumothorax. Chest 1999;116:676681.

11 Sadikot RT, Greene T, Meadows K, Arnold AG: Recurrence of primary spontaneous pneumothorax. Thorax 1997;52:805-809.
12 Lippert HL, Lund O, Belgvad S, Larsen HV: Independent risk factors for cumulative recurrence rate after first spontaneous pneumothorax. Eur Respir J 1991;4:324-331.

13 El Sonbaty MR, Bitar ZI, Marafie AA, Sharma PN: Primary spontaneous pneumothorax in Arabs: does its frequency differ from elsewhere? J Clin Epidemiol 2000;53:631633.

14 Taussing LM, Cota K, Kaltenborn W: Differ ent mechanical properties of the lung in boys and girls. Am Rev Respir Dis 1981;123:640643.

15 Baumann MH, Noppen M: Pneumothorax. Respirology 2004;9:157-164.

16 Moody PM, Memon A, Sugathan TN, ElGerges NS, Al-Bustan M: Factors associated with the initiation of smoking by Kuwaiti males. J Subst Abuse 1998;10:375-384.

17 Scott GC, Berger R, McKean HE: The role of atmospheric pressure variation in the development of spontaneous pneumothorax. Am Rev Respir Dis 1989;139:659-662. 